\title{
A View of the World
}

\section{Toward a Photographic Theory of Cel Animation}

The art of photography has been persistently haunted by the image of human labor.

- ALLAN SEKULA ${ }^{1}$

I like to think of each image-whether it contains accidents or not-as a view of the world. They reveal traces of the humans and technology that produced them.

-ANDREW NORMAN WILSON ${ }^{2}$

\section{THE ART OF PHOTOGRAPHY}

For most of the twentieth century, to animate was to photograph-and to photograph a lot. A theatrical split-reel short produced by an animation studio might involve five to ten thousand separate frames. Like most photographic archives, from microform periodicals to crime galleries to geographical surveys to digitized books, works of cel animation were produced under tightly regulated conditions. Following frame-by-frame instructions enumerated on exposure sheets, camera technicians took picture after picture after picture, and as has been routinely acknowledged, their task was uniquely "tedious," "mechanical," "monotonous," "enervating," "exacting," and "exhausting." 3 The operator of the animation camera was a "proletarian of creation," Bernard Edelman's term for the nineteenth-century photographer who, responsible for "merely deploy[ing] an apparatus," had no authorial or legal claim to the images he produced. ${ }^{4} \mathrm{He}$ adhered to the sort of "strictly determined routine of distance, camera angle, lighting, and type of lens and apparatus" familiar to police photographers: which cels to add, which to remove, how to position the camera relative to the background, and so on. ${ }^{5}$

The mechanization of the labor process by which animation's constitutive frames were photographed has led to a curious and perhaps paradoxical 
phenomenon: the complete disavowal of cel animation as photographic cinema. As Shamus Culhane, who worked with many of the major studios, explained to the trade journal Sponsor in 1955, "the camera plays a relatively small role" in animation. The task of the camera operator was enormous and often daunting, but the creative force he exerted on the final film (even though it would not be a film without his intervention) was artistically negligible: "Unlike the camera in live-action which actually creates, the animation camera merely records what has already been created." ${ }^{\circ}$ Culhane's remarks anticipated a commonplaceindeed, foundational-assumption in film theory: an ontological divide between animation and photography.

Dudley Andrew, for instance, regards the photographic process as more or less incidental to animation, a mere stopgap between the flip-books and phenakistoscopes of yesteryear and the computer-generated imagery of today: "Cel animation has always amounted to a camera-less cinema." 7 This is a very curious claim. For instance, rayographs and photograms are, by definition, camera-less, which makes them more "truly" indexical than traditional photographs. Besides, even handmade films and works of direct animation, such as Len Lye's A Color Box (1935) and Stan Brakhage's Mothlight (1963), circulate in the form of prints; although made without a camera, they nonetheless rely on photochemical and photomechanical technology for the purposes of distribution and exhibition. ${ }^{8}$ "Camera-less" cinema, in all its forms, thus troubles ontological assertions about photographic indexicality.

But photography, of course, is many things. As Hollis Frampton has outlined, it is an industry, a craft, a technology, a tool, a science, a trade, a racket, a hobby, a national pastime, and only rarely an art. It is an instrument of state control and sells lipstick and preserves moments we would rather forget. ${ }^{9}$ The automated, large-scale photographic practice I have detailed above could perhaps lead one to place animation in the same category as archival and disciplinary photography, which is inflected with what John Tagg has called the rhetoric of documentation, the rhetoric "of precision, measurement, calculation and proof, separating out its objects of knowledge, shunning emotional appeal and dramatization, and hanging its status on technical rules and protocols whose institutionalization [has] to be negotiated." ${ }^{10}$ But in calling attention to the photographic processes undergirding cel animation, I wish instead to place animated cartoons within the discourses that have long dominated film theory. The basic, undeniable fact that cel animation was a photographic process is almost always treated as an orthogonal concern, if it is acknowledged at all. ${ }^{11}$

The most influential (and perhaps most misunderstood) such theory derives from André Bazin's “Ontology of the Photographic Image” (1945), which has served as the basis for countless claims about cinema being a photographic medium first and foremost. Of course, Bazin equivocates on just what photography is-a snowflake? a fingerprint? - but one thing is clear: cinematic realism is, as he puts it 
elsewhere, irresistible. ${ }^{12}$ Anchored in "the irresistible realism of the photographic image," cinema gives us a tantalizing vision of everyday reality. ${ }^{13}$ It makes sense that animated cartoons should be excluded from this account of cinema, and indeed I cannot pretend I might convince Bazin otherwise. Nevertheless, I wish to take a governing premise of Bazin's film theory-that "the realism of the cinema follows directly from its photographic nature" - and apply it literally, almost pedantically, to the thoroughly unreal worlds inhabited by the likes of Popeye, Daffy Duck, and Mickey Mouse. ${ }^{14}$ While graphic in origin, these worlds are only visible to us because their constitutive elements (glass, cels, ink, paint, paper) have been photographed.

D. N. Rodowick and Mary Ann Doane are among the rare theorists to acknowledge the role of the camera in the production of animation. Rodowick notes that cartoons "obviously have a strong indexical quality," for "here, as in all other cases, the camera records and documents a past process that took place in the physical world." Doane, similarly, observes that "animation involves photography and a 'that has been' of the graphic image in front of the lens." ${ }^{15}$ What is evident from these remarks, however, is that both Rodowick and Doane are invested first and foremost in the putative indexicality of the cinematic image. Animation, for them, is but a parenthesis, and in this case one that happens to shore up-not test-the boundaries of photographic possibility. Neither goes so far as to find out what happens if one were actually to watch an animated cartoon as a photographic record of graphic images.

This chapter picks up where Rodowick and Doane leave off. The previous chapter, by contrast, took for granted photography's objectivity-which is to say, its transparency-struggling only to pass through the spatial and temporal barriers erected by the medium. Thanks to photography, hundreds of thousands of images that would otherwise be lost has been preserved. In this chapter, however, my effort to situate animation within photographic theories of film forces me to reckon with the medium as such: as a barrier, as something that comes between the viewer and the world it discloses. Such a reckoning is necessary due to the nature of the objects that have been photographed. As it turns out, it is not always easy, and it's sometimes impossible, to sort out what has been produced graphically (and then reproduced photographically) and what has been produced by the camera-that is, photographically. The fiber of the background watercolor paper intertwines with the grain of the film; what looks at first to be specks of dust that have adhered to the cel might in fact be cartoon raindrops or scratches in the film emulsion. A hair in the gate is often indistinguishable from a squiggly line of ink; what seems to be an explosion of dynamite in the upper-right corner of the frame could just as easily be a cue for the projectionist to change the reel. In the case of Shamus Culhane's The Painter and the Pointer (Universal, 1944), a faint greenish ring is burned onto a frame in which a spider, having been set in motion by a companion's slap, is depicted as little more than a black-and-white circular blur. In 

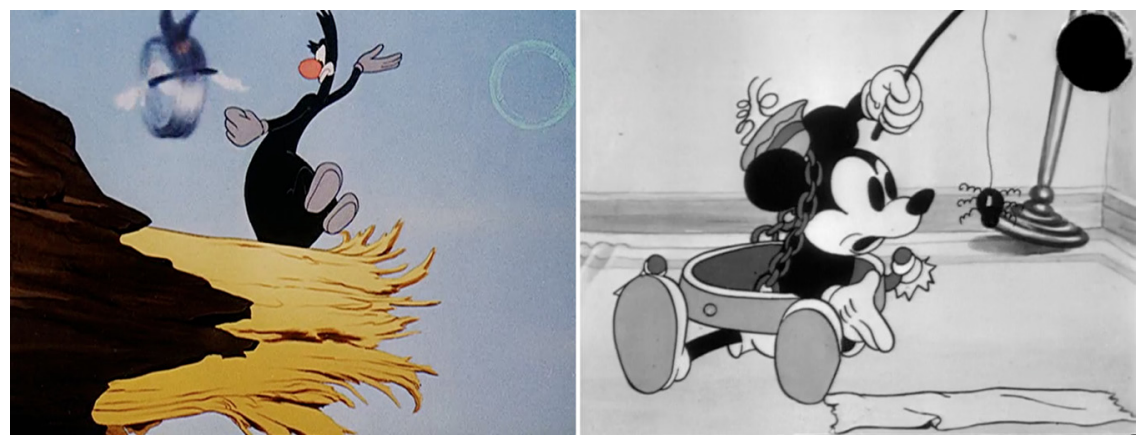

FIGURE 2.1. Frames from The Painter and the Pointer (Universal, 1944) and Gulliver Mickey (Walt Disney, 1934).

Burt Gillett's Gulliver Mickey (Walt Disney, 1934), meanwhile, the black circles that are Mickey's ears are just about the same size, shape, and color as the hole punched into the frame (fig. 2.1).

The epistemological concerns that emerge (for instance, is what I am seeing on the cel, on the camera lens, in or in front of the projector, on the film emulsion, a digital artifact, on the screen?) become a site of aesthetic inquiry. Thus we move away from the complaints of microfilm reviewers like Lawrence Cummings, who, you will recall, bemoaned his inability to distinguish between Sir Walter Raleigh's handwriting and "an interesting pattern of wrinkles." ${ }^{16}$ Insofar as they destabilize our sense of cause and effect and prevent us from seeing what the photograph is supposed to represent, these flaws would normally impede the value of the photograph as evidence. But the anxiety they engender can also be productive: it can mobilize an inquisitive gaze that plays with and within the image. Rather than worry that we cannot ever know what it is that we are looking at, we delight in the masquerade. Forensic investigation becomes a game.

Consider some of the common criticisms of microform: for instance, that the photographers were working from uncut bound volumes, resulting in "distortions, blurring, curling, and loss of text," or that they had neglected to clean the camera lens properly, as evidenced by "the identically shaped blobs, splotches, and squiggles which show up constantly from frame to frame." ${ }^{17}$ These criticisms privilege the legibility of the source document: the medium should be transparent. But one could instead embrace the uncertainty. Instead of resolving the tug-of-war between the photograph's own materiality and the material object it represents, between the world of the image and the world that has made the image come into being, we enter into the image.

In what follows, I will analyze the visual aesthetics of animated cartoons as if the constitutive frames were each a photograph in one of the family albums 
famously described by Bazin: "No matter how fuzzy, distorted, or discolored, no matter how lacking in documentary value the image may be, it shares, by virtue of the very process of its becoming, the being of the model of which it is the reproduction; it is the model. ${ }^{\prime 18}$ Yet this chapter also takes instances of fuzziness, distortion, and discoloration not as barriers through which we pass in order to satisfy our need for the material object, but as part and parcel of photography's own materiality. I begin with Bazin, oriented toward a view of the reproduced object, and I end up embedded in the material substrate of the film itself. A realist theory of cinema, when applied to animation, results in something closer to a structural and materialist theory of cinema. ${ }^{19}$

\section{TRACES OF THE WORLD}

Animation is phantasmagoric, in the sense advanced by Karl Marx in Capital and developed by Theodor Adorno in his writings on Richard Wagner: animated cartoons seem to be self-producing. For Adorno, Wagner's operas are characterized by an "occultation of production"; they "make us forget that they have been made." Their closest analogue, he continues, is "the consumer goods of the 19thcentury which knew no greater ambition than to conceal every sign of the work that went into them, perhaps because such traces reminded people too vehemently of the appropriation of the labor of others, of an injustice that could still be felt." ${ }^{20}$ Adorno's suspicions about the relationship between the work of art and the commodity are confirmed by a passage in Honoré de Balzac's Modeste Mignon (1844): "You, under the arbor of clematis where you dream over poetry, cannot smell the stale cigar smoke which depoetizes the manuscript, just as when you go to a ball, dressed in the dazzling products of the jeweler's skill, you never think of the sinewy arms, the toilers in their shirt-sleeves, the wretched workshops whence spring these radiant flowers of handicraft." ${ }^{21}$

We see this same phantasmagoric impulse guide how we immediately, naturally, physiologically respond to the animated cartoons produced by an industry repeatedly roiled by labor strife. Such is the power of movement and, hence, of animation-or, as Sergei Eisenstein famously phrases it, "If it moves, then it's alive; i.e., moved by an innate, independent, volitional impulse." So potent is this sensation that it overwhelms our ability to see animated cartoons as human- and machine-made, as animated by anything but themselves:

We know that they are ... drawings, and not living beings.

We know that they are ... projections of drawings on a screen.

We know that they are... "miracles" and tricks of technology, that such beings don't really exist.

But at the same time:

We sense them as alive.

We sense them as moving, as active.

We sense them as existing and even thinking! ${ }^{22}$ 
To remember that animation is photography is not enough, for memory cannot compete with the present tense of the animated cartoon. Eisenstein is attracted to animation because it returns the viewer to a pre-logical state in which thought and movement are undifferentiated. Because it moves, it thinks. Because it thinks, it moves. It doesn't need outside intervention.

The world of the animated cartoon is not the world, is not our world. While a photograph is both indexical (insofar as it is the direct product of a past process) and iconic (insofar as we can recognize what it represents), an animated cartoon is merely iconic. Its caricatured figures can bear a physical resemblance to real people, animals, and things, but not their physical traces. Thus, while an animated cartoon may be produced photographically, it is not photographic.

Sean Cubitt, for one, treats animation as a conceptual paradigm distinct from photography: "Photographic frames reproduce, but animated frames produce." This is an outgrowth of Lev Manovich's observation that animation's "visual language is more aligned to the graphic than to the photographic." ${ }^{23}$ And Stanley Cavell puts it bluntly: "Cartoons are not movies." Cavell allows that animated cartoons create a world, but what is most important for him is that their world is not the world. In this respect, an animated cartoon is like a painting, in that it "is a world," not a photograph, which is, Cavell emphasizes, "of the world." 24 The frame of a painting is centripetal, pulling us inward, toward a world found only within its borders; the photograph, by contrast, is centrifugal, pushing us outward, beyond its bounds: a window. Thus live-action cinema offers us one thing, a view of the world, and cel animation offers us something different, $a$ world governed by a physics all its own, a plasmatic and limitless world where bodies never bruise and anvils are always falling from the sky.

We should not mistake what little the two forms share-a mode of exhibition, for instance-for an ontological equivalence. We should no more confuse them than we should opera and ballet (which share the stage) or a print advertisement and a muckraking exposé (which share the page). Yuri Lotman's brief essay "On the Language of Animated Cartoons" (1981) offers a concise account of the relationship between animation and live-action cinematography: cartoons do not offer "some image of the outside world," as a photograph does, "but rather an image of the outside world expressed in the idiom of a children's drawing." ${ }^{25}$ Indeed, the two forms seem to speak different languages: animation deals in "signs of signs," as Lotman puts it, and hence, according to Fredric Jameson, constitutes "the first great school to teach the reading of material signifiers." ${ }^{26}$ For Lotman and Jameson, as for Benjamin and Eisenstein, animation's great power is its ability to offer a world unconstrained by the outside world. "We who have suffered since birth from an incessant pull at our coat-tails by centripetal forces, who tiptoe through life avoiding evilly-set obstacles," writes the artist Jean Charlot, "rejoice when flung into the world of animation where our moves impose their own elbow room over all creation." ${ }^{27}$ But for other theorists, this is exactly animation's shortcoming. Its only referent is itself. 
For this reason, Dudley Andrew excludes animated cartoons from participating in "the enterprise of cinema in toto," which is to take the viewer on "voyages of discovery," voyages impossible in a world as regulated and controlled-down to the last frame-as that of a cartoon. If animation were to be considered cinema, it would have to be the kind that "lies and agitates," not the kind that aims "to discover, to encounter, to confront, and to reveal. ${ }^{{ }^{28}}$ For Andrew, animation resides in the same category as a film like Jean-Pierre Jeunet's Amélie (2001), a key sequence of which Andrew describes:

In the film's prologue, Amélie plays up to us, describing herself as a film spectator with a prehensile eye: "I like noticing details that no one else does ..." she whispers from her seat in a movie theater. And to prove it she isolates an accident visible in a famous shot from Truffaut's Jules and Jim (Jules et Jim, 1962), an insect that somehow made it on camera, crawling on a glass in the rear plane of the shot seemingly right toward Jeanne Moreau's sensuous mouth as it opens to receive Jim's tender kiss. ${ }^{29}$

Yet, as Andrew then notes, Amélie is itself incapable of offering its spectators any such pleasure, no matter how roving one's eye, for "Jeunet has digitally erased every unsightly or merely incongruous element, frame after frame. That insect that Amélie delighted to spot in Jules and Jim would not have survived Jeunet's image scrubbing." ${ }^{30}$ It is for this reason that Amélie, according to Andrew, is not cinema: it denies its viewer the chance to experience the very cinephilic moments its main character loves. Andrew's critique of works like Amélie and his preference for works like Jules and Jim is indebted to the division Bazin draws between "those directors who put their faith in the image [e.g., Jeunet] and those who put their faith in reality [e.g., Truffaut]. ${ }^{31}$ And reality, replete with unsightly insects, has no place in the animated cartoon, either.

How Andrew understands film's powers and potentialities, particularly vis-àvis his critique of Amélie, becomes clearer through an examination of Howard Hawks's Twentieth Century (1934). At first glance, Hawks might seem to lack faith in reality. He is a paradigmatic auteur, to be sure, but what, exactly, is cinematic about Twentieth Century? What separates Hawks's realization of the script from the theatrical staging of the play from which the film was adapted? A stage production, true, could never give us Carole Lombard's luminous face in close-up, but such shot scale is the exception in a film dominated by medium and long shots. Yet this very simplicity, this very rigor, is what emboldens Andrew Sarris, in his appraisal of Hawks, to call the director's films "good, clean, direct, functional cinema"-the last qualifier an echo, perhaps, of Jacques Rivette's assessment six years earlier: "There seems to be a law behind Hawks's action and editing, but it is a biological law like that governing any living being: each shot has a functional beauty, like a neck or an ankle." ${ }^{2}$ For Sarris, Hawks's straightforward style is "endowed with a human intimacy," while, according to Rivette, "Hawks first of 
all concentrates on the smell and feel of reality." ${ }^{33}$ Still, one could easily level the opposite criticism: the close contact Hawks seems to give the viewer is instead as artificial and flimsy as his sets. The compartments on the New York-bound train that give the film its name are intimate, granted, but also small is the camera's depth of field. As a consequence, the action of the scene is staged entirely on one lateral plane, and how very staged it is! A case might be made, over Sarris's and Rivette's earnest protestations, that Twentieth Century amounts to little more than canned theater. What is there to discover here?

Even the most skeptical critic would come face-to-face with reality in a scene near the film's conclusion. Under the tutelage of theater producer Oscar Jaffe, played by John Barrymore, Lombard's Mildred Plotka has blossomed into Lily Garland, star of the Great White Way. In their first rehearsal together, Jaffe, frustrated with her incompetence, charts with a chunk of chalk every step Garland née Plotka should take over the course of the scene. The resulting tangle of white lines against the black floor provides, then, a map of her movement across the stage. At once the spontaneous expression of Jaffe's mania and the prescribed path from which Garland is not to deviate, the map offers, too, a potent symbol for one of the film's central themes: the opposition, as Gerald Mast writes, between "acting and living, playing scenes and feeling emotion, the theatrical and the real." "34 These tensions are articulated in the film's final act, in which Garland and Jaffe hash out the ups and downs of their relationship: "We're only real between curtains," Garland says at one point. The scene, which lasts more than seven minutes, is set within a train compartment and consists primarily of medium two-shots, some of which are thirty seconds or longer. Like Hawks's Rio Bravo (1959) a quarter century later, Twentieth Century was shot almost entirely in a studio, which is quite apparent from the fact that we only ever see three of the train compartment's walls. All of the shots in the entire seven-minute stretch are static, save for one, when the camera dollies laterally in order to capture Jaffe, overcome by pique, as he strides away from Garland. His mouth and hands contort in an imitation of a masticating camel, one of the hundred he hopes to wrangle onstage in the Passion play that will be his and Garland's comeback show. When Jaffe turns back to Garland, the camera again travels along with him. The extremes to which Barrymore takes his performance-the speed, for instance, with which he suddenly transforms into a camel and then snaps back to his old self-makes the camera's parallel movements seem spontaneous, as if Barrymore were given free rein to improvise, yet the fluidity with which the camera is able to follow him indicates that his every gesture has been rehearsed in advance.

Five minutes into the scene, the emotions are running high. "You're crazy!" shouts Garland at Jaffe, waving her hands in disbelief. Suddenly the frame is punctuated by one small, quite nearly invisible detail: set off against the white of the back wall, a fly zigzags across the screen, flitting from one side of Jaffe to the 
other, and back again. No amount of chalk on the floor could dictate the path the fly takes-first it is here, and then it is there, and then it is gone. It serves no narrative purpose. Garland does not use its abrupt appearance as proof of her former lover's worthlessness. Barrymore does not pause in his performance to brush it away. It is no more and no less than a fly that has happened to flit onto the set.

This brief disruption is a perfect example of what Christian Keathley calls "those fortuitous, chance encounters that are regularly captured by the camera in spite of the operator's intentions." 35 Although these "encounters" often fall under the category of "goof" or "error," I follow Keathley and Andrew in arguing that they do not detract from the viewing experience. Instead, they are the sorts of details that give heft to the reality of the world both inside and outside the film. To see that fly is to discover that fly. The film suddenly contains artifacts to be unearthed and histories to be reconstructed: the fly is one of those "secondary' details," identified by Bazin, that are "apparently aesthetically at odds with the rest of the work," but "give it its truly cinematic quality." 36

\section{THE INDEX OF THE ARTIST}

As it so happens, animated cartoons contain countless such secondary details. How could they not? Consisting of thousands upon thousands of individual photographs, cartoons cannot help but reveal the world. Or, as the artist Andrew Norman Wilson puts it in the epigraph to this chapter: "They reveal traces of the humans and technology that produced them." Dust accrues on the cels; a stray thumbprint leaves a lasting impression; paint is applied inconsistently from one cel to the next. "In many ways, the one behind the camera has to be the most patient person in the studio," Shamus Culhane acknowledges. "Animators scribble illegible numbers in the exposure sheets; checkers stack cels out of sequence; at one in the morning, a cel is found to be missing-the list of possible mishaps is endless." ${ }^{37}$ Some of these mishaps, when they escape the camera operator's notice and are recorded for posterity on film, betray the photographic origins of cel animation: they are made visible after the photographic apparatus brings them literally to light. Others only become apparent in the succession of frames, in the difference between images: a portion of a cel goes unpainted, creating a strange pulsation of white or black; several frames in a walk cycle are dropped, producing a barely perceptible stutter in a character's movements; the differences in illumination between cel layers is unaccounted for, such that characters change shades of gray from one frame to the next; cels are mislayered before the camera. Of course, these examples never succeed in fully "breaking" the spell of the cartoon's world. Rather, they are tiny intrusions that divert our gaze for a split-second, if that-pinpricks in an otherwise vacuum-sealed world. 
The incongruous insects of animation are the mistakes attributable to the studio's inkers, painters, camera operators, and other below-the-line workers-an index of their presence.

Due to industrial controls, the actual hand of the photographer never makes its way into works of cel animation. But animated cartoons produced by more artisanal methods, such as Raoul Barrés slash-and-tear system, are here and there marred by an errant hand. Because he did not have to take the step of lowering and cleaning a glass platen, a tired or rushed camera operator could easily neglect to remove his hand from the frame before taking a photograph. Many 1920 s cartoons thus accidentally test what Donald Crafton calls the trope of "selffiguration," or "the tendency of the filmmaker to interject himself into his film," often through the deliberate inclusion of the putative hand of the animator in the image. As Crafton has argued, installments in Max and Dave Fleischer's Out of the Inkwell series and Walter Lantz and J. R. Bray's Dinky Doodle series, as well as variations on the "lightning sketch" routine showcased in James Stuart Blackton's Humorous Phases of Funny Faces (1906), offer "the exhilarating sensation that life is somehow being created before the spectator's eyes." ${ }^{8}$ But sometimes a hand appears when and where it should not. The camera operator's hand is captured in several frames throughout the Fleischers' Jumping Beans (1922, fig. 2.2), for instance, while in Animated Hair Cartoon No. 18 (Red Seal Pictures, 1925, fig. 2.3), distributed by the Fleischers' Red Seal Pictures, another such hand is photographed in the midst of the stop-motion transformation of a portrait of George Bernard Shaw into that of the baseball commissioner Kenesaw Mountain Landis. Each instance alerts us to the inefficiencies and irregularities that made slash-and-tear uneconomical for large-scale production and to the flatness and graphic clarity and purity of these early cartoons, against which the volumetric, gray-toned, and inconsistently lit human hand resembles a bas-relief. For a splitsecond, the hand of the worker appears on-screen; for a split-second, an icon of the worker's labor becomes visible.

Importantly, these moments hold out an aesthetic interest-and that is what makes them more than mere continuity errors. They pull against the space of the frame, directing our attention outward, centrifugally. But they also push inward, in that they make the peripheral detail the central axis of the screen. Robert Breer's Fuji (1974) provides an example of how this aesthetic possibility erupts. While Fuji is a work of experimental animation, not an animated cartoon, it can be considered a limit case that differs only in degree from Jumping Beans. Fuji is a study of flatness and depth, of movement and stillness. Most of the film consists of footage Breer first shot with a Super- 8 camera while traveling by train in Japan and then rotoscoped (traced frame by frame) onto index cards using pencils and markers. As the footage unfolds, the film tests the iconicity of Mount Fuji: what does it take for it to be identifiable? As it turns out, just a tiny black triangle can 

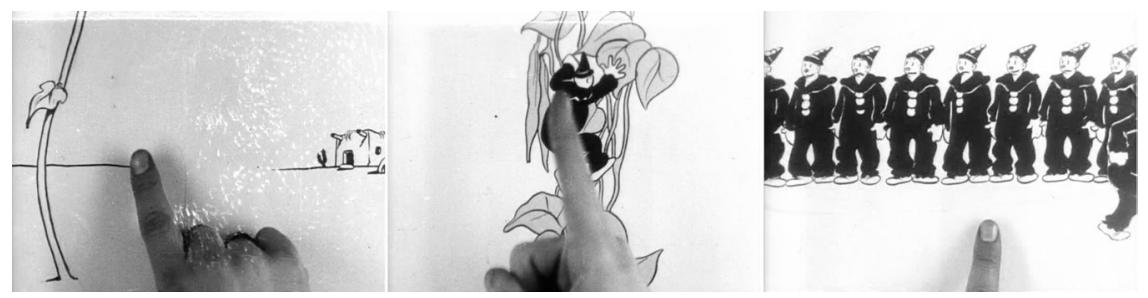

FIGURE 2.2. Anomalous fingers in Jumping Beans (Fleischer Studios, 1922).

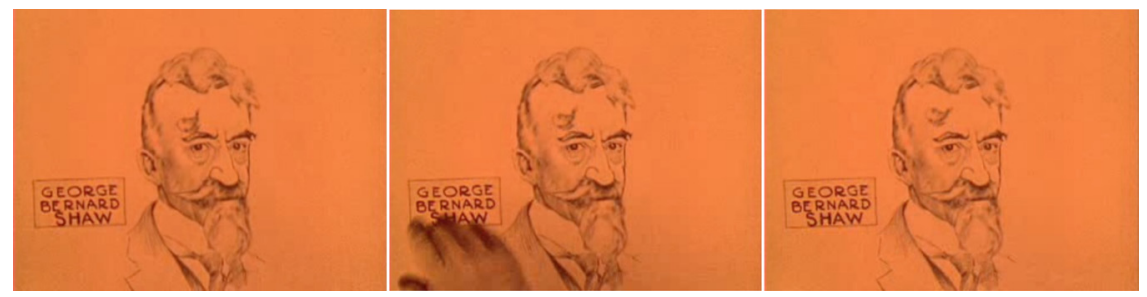

FIGURE 2.3. Three successive frames from Animated Hair Cartoon No. 18 (Red Seal Pictures, 1925).

be enough, or even an upside-down V. Around the time Breer was working on Fuji, Roland Barthes found himself looking at his own index card collection and musing on this very question:

In the blue lining of an envelope that [by] chance, after detaching it from its backing, outlines against a partition in one of my boxes, I suddenly see the silhouette of Fujiyama; and so, playfully, on top of the crater I place a faint cloud inside which I write-since this is the function of my box- "to be filed." 39

In Breer's film, this experiment in gestalt plays out on the surface of the screen, and we understand Yuri Lotman's argument that the language of the animated film is the idiom of the children's drawing. At the same time, that the footage has been rotoscoped gives us the sensation that something has been covered up and now lurks just below the surface of the image. At the outset of the film, Breer provides glimpses of the source footage, but these then recede beneath the layers of index cards and ink. Only one frame breaks both the rhythm of the film and the dynamic tension between the photographic Mount Fuji and the graphic Mount Fuji-a frame in which Breer's hand comes from above, having been captured in the moment of reorganizing the cards in front of the camera lens. The dramatic shift in the scale and depth of the image momentarily points outward, while affirming the dynamism of the drawings Breer is fingering (fig. 2.4).

The hand is a convenient heuristic by which to measure labor. For this reason, as Allan Sekula notes, it often stands as a synecdoche for the "working body" 


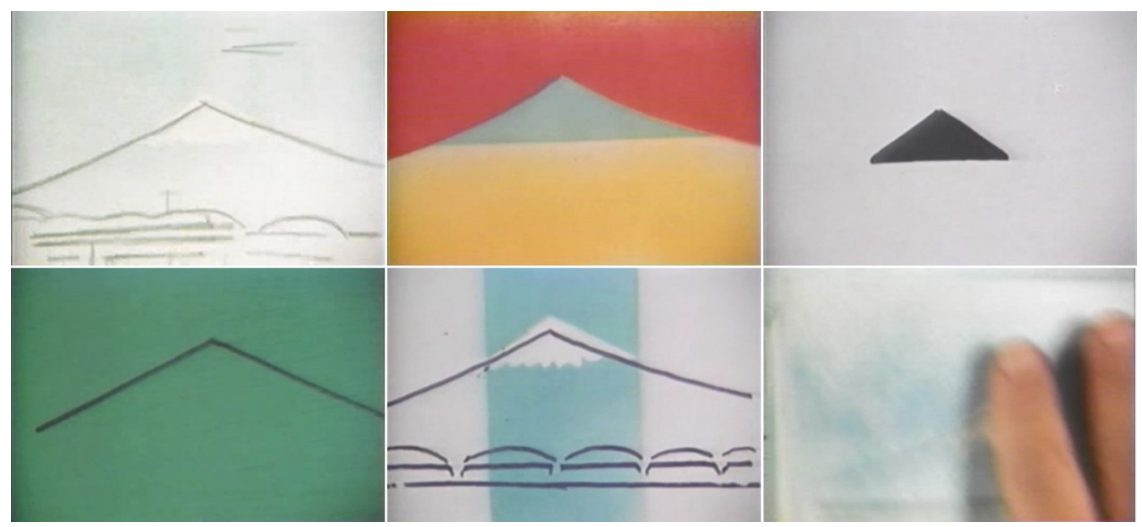

FIGURE 2.4. Five views of Mount Fuji and one view of the artist's hand in Robert Breer, Fuji (1974).

in modernist photography (as in László Moholy-Nagy’s photograms, in which negative silhouettes of his hands figure prominently). ${ }^{\circ}$ But these examples I have cited are exceptions. Rare is the animated cartoon that shows us exactly what we want to see. More often than not, the photograph seems untouched. We must look for what isn't there. Or, rather, we must look at and into what is there: the photograph itself.

\section{TRACES OF PRODUCTION}

A six-second sequence in Friz Freleng's Hare Force (Warner Bros., 1944), an otherwise inauspicious installment in the Merrie Melodies series, is rife with all sorts of marginal and often unintentional details-mishaps, accidents, mistakes, errors, clues. A dog, engaged in a heated rivalry with Bugs Bunny, visualizes the ways Bugs could meet his demise: by stabbing, by cannon blast, by being hacked to bits. The cel setup is relatively simple. The dog is painted to simulate a medium closeup. Although his torso barely moves throughout the sequence, subtle variations in its outer contours and the folds of his shoulder from frame to frame indicate that his head and upper body were painted on a single cel-not, as is often the case, on separate cels, which would have allowed animators, inkers, and painters to redraw and repaint only his face. While time-consuming, painting the entirety of his body on a single cel did afford an advantage. Acetate cels are not completely transparent, so when additional cels are overlaid, the colors of the cels below darken. Even a stack of two cels would have required the painters to "compensate" for this minute difference in tones by mixing separate tones for each cel-also time-consuming, and sometimes an impossible task in its own right. (In another sequence later in the film, the body has been painted on a lower cel and remains unchanged 
while the head contorts wildly. Each layer was painted the same color, but the body appears brown, the head closer to burnt orange.) Meanwhile, the dog's vengeful reveries appear above his head in the form of thought bubbles, which are rendered in white ink on cels that overlay the one on which the dog is painted. Each one is held on-screen for approximately two seconds, enough time for the audience to register the sheer cruelty of the fantasies and then marvel at the shifts in the dog's facial expressions-the quirk of an eyebrow as his ideas begin to tickle his fancy, the lips pulling back in a malicious grin. Against the black background, the white sketches read like chalkboard drawings. The line has a rare hastiness and urgency for cartoons of this period.

But it is the black background of the scene that ultimately provides the greatest fascination. Large dark areas in the image field were notoriously difficult for camera operators to light properly. As Disney layout designer Ken O'Connor once noted, the lights "tended to grey out the black," and, in addition, "the black background paper was excellent for bringing out any dust specks," ${ }^{41}$ a point made clear in a later sequence in Hare Force: Bugs, isolated in medium shot, is orbited by a tiny, evershifting galaxy of white spots. Furthermore, intervening between the black background and the camera were several layers of transparent cels, onto which sweat and oil could easily rub, and a glass platen, which was used to secure the cels and background but also made the task of lighting the image consistently all the more difficult. And, sure enough, in the photographs of the dog, a faint orange glow is visible on the left side of the frame. Almost the same hue as the dog's fur, it has been produced not with a paintbrush but by the lights of the animation camera. Halfway through the sequence, when the dog imagines Bugs facing down cannon fire, four or five blue streaks also appear just above the orange glow. These streaks are arranged like the fingers and thumb of a hand-and, indeed, they are most likely the result of the cel having been handled by one of the anonymous workers on the animation assembly line (perhaps an inker, perhaps the camera operator). A black background, rather than evacuating depth from the image, in fact gestures to the world outside (above and before) it. This single sequence illuminates both the dog's brutal fantasy world and the material facts of its production.

Hare Force is but one installment in the Merrie Melodies and Looney Tunes series, which number more than a thousand and are joined by the thousands of other works of cel animation produced by major US studios. The accidents Hare Force discloses are by no means exceptional-nor is the fact that it discloses these accidents at all. Of course, it is easy to watch Hare Force without ever noticing what I have described. My ability to understand what I am seeing is informed by my knowledge of the production process. Yet that knowledge only goes so far. I will never gain access to the exact conditions under which the film was produced. What I have identified as dust might be dandruff; what is visible on DVD and $35 \mathrm{~mm}$ might be concealed in a reddened $16 \mathrm{~mm}$ print; what I read as the prints of five separate fingers might all be the residue of a single thumb. I can stop the 
film, look and stare, and still be uncertain. I do not have full knowledge of the world the photograph reproduces. Instead, it is my imagination that it is activated. Consider Oliver Wendell Holmes's analysis of the "lesser details" and "incidental truths" of stereograph cards. "The more evidently accidental their introduction, the more trivial they are in themselves, the more they take hold of the imagination," he writes. Whether examining two successive frames of an animated cartoon as if they were "twin pictures" in a stereograph or watching the film at twenty-four frames per second, one can surrender to the glimpses, the hints, of the lives and worlds that these images offer us. To Holmes, an out-of-focus figure in the corner of a photograph writes "a hundred biographies in our imagination," and so too can one hypothesize-fantasize-about what human fallibilities gave way to the imperfections enumerated above. What "longings, passions, experiences, possibilities" yielded what we see? ${ }^{42}$ Boredom? exhaustion? frustration?

When the film is projected at proper speed, some of the mistakes barely register-blink and you'll miss them. But even a mistake in a single frame can quake the world of the film. Did I just see that? Other anomalies operate on an aesthetic register apart from the world of the film, reshaping our perception of an entire scene. Many of these are the result of mistakes made earlier in the production process. Inkers and painters, for example, encountered difficulties in translating animators' sketches onto cels. Try as they might, they could not always control the consistency with which they applied colors. As a result, the dresses worn by Mama Bear in Tex Avery's The Bear's Tale (Warner Bros., 1940) and Witch Hazel in Chuck Jones's Broom-Stick Bunny (Warner Bros., 1956) churn and shudder within the contours carefully delineated by the Ink Department; their streaks of brown and blue appear to move of their own accord, performing serpentine dances of lighter and darker swirls. (A similar effect is achieved in stop-motion animation: the manipulation of fur, fabric, or clay of a figure from frame to frame produces an effect known as "boiling.") Frequently, cels were painted the wrong color or not at all. As Snow White tends to the well in Walt Disney's Snow White and the Seven Dwarfs (1937), a patch on her skirt moves around and changes from light blue to purple; in Bob Clampett's Falling Hare (Warner Bros., 1943), the gray and white of first Bugs Bunny's tail and then his leg switch places; in Freleng's She Was an Acrobat's Daughter (Warner Bros., 1937), the polka dots on a woman's dress come and go. Struck by the lacuna that is animation's absence from film theory, Tom Gunning has pressed for a returned attention to the motion of motion pictures. As he argues, following Eisenstein, this motion "need not be realistic to have a 'realistic' effect, that is, to invite the empathic participation, both imaginative and physiological, of viewers." ${ }^{43}$ When a patch on Snow White's dress changes color or position from frame to frame, we perceive these mistakes as movement-as, indeed, animation. That tiny rectangle is suddenly endowed with a life of its own, a life apart from either Snow White or Snow White. It is like fire or smoke or water, like a billowing curtain or trembling leaves. 
It was not the camera operator's job to catch such mistakes-after all, cartoon bodies routinely mutate, so how could he be expected to know what, indeed, was unintended? But the camera, regardless, captured them unblinkingly. Other common mistakes, meanwhile, might very well be the fault of a tired or harried camera operator not following directions: uniformity breeds monotony, monotony breeds boredom, boredom breeds carelessness. Rudy Ising, an animator who worked as a cameraman for Walt Disney before starting his own studio with Hugh Harman, recalled frequently falling asleep between exposures. ${ }^{44}$ The affinities between animation and microfilm photography are here apparent. For instance, a 1957 essay titled "The Case against Microfilming" highlights the many difficulties of transferring an office's records onto microfilm: "When you have a variety of materials to photograph, including papers of different reflective qualities, different colored inks or the like, the operator must make constant simple adjustments that slow down the operation until the operator gets bored and suddenly the filming speeds up. The result is no joke." 45 The results for animation, meanwhile, are often quite funny. Cels, if stacked in the wrong order, can reveal imperfect or impossible bodies. In Dave Fleischer's Popeye Presents Eugene the Jeep (Paramount, 1940), Popeye spends most of a scene behind a table before exiting screen right. In one frame, however, one sees a portion of his body that was supposed to be covered by the tablecloth: his leg is inked but unpainted, and someone has crossed it out (most likely as a signal to the Paint Department to forgo that half of his body) (fig. 2.5).

As a scene unfolds, a cel might be forgotten, if it made it to the Camera Department at all, and a character will disappear for a split-second. In Avery's Gold Diggers of ' 49 (Warner Bros., 1935), a cowboy hippopotamus jumps onto a horse that, for one frame, isn't there to catch him, while a gurgling baby loses a leg in Freleng's Foney Fables (Warner Bros., 1942). In a sequence in Jones's HairRaising Hare (Warner Bros., 1946), Bugs Bunny attempts to keep the fearsome monster Gossamer from barreling through a door. He arches every part of his body-his feet, his back, and even his ears-to hold closed the bending door. "Is there a doctor in the house?" he calls out to the audience in desperation, his head turning toward the fourth wall. A split-second before a silhouetted figure leaps up to answer his cry, Bugs's head disappears for a single frame (fig. 2.6). The rest of his body remains, retaining its contorted pose. Just like that, we realize he has been painted in sections, his head on one cel and his body on another, and we see both the total coherence of Bugs's graphic design (insofar as every part of him is reacting in some way to Gossamer's physical threat) and the completely fragmented labor process that necessitated dividing him across several cels.

Very rarely, a cel might be accidentally placed before the lens with its verso side facing up. A character's outlines were inked on the front of the cel and then sent to the Paint Department, the women of which opaqued the back of the cel in order to preserve the integrity of the inked contour. A view of the verso side reveals the painter's brushstrokes, particularly where she did or did not trespass 


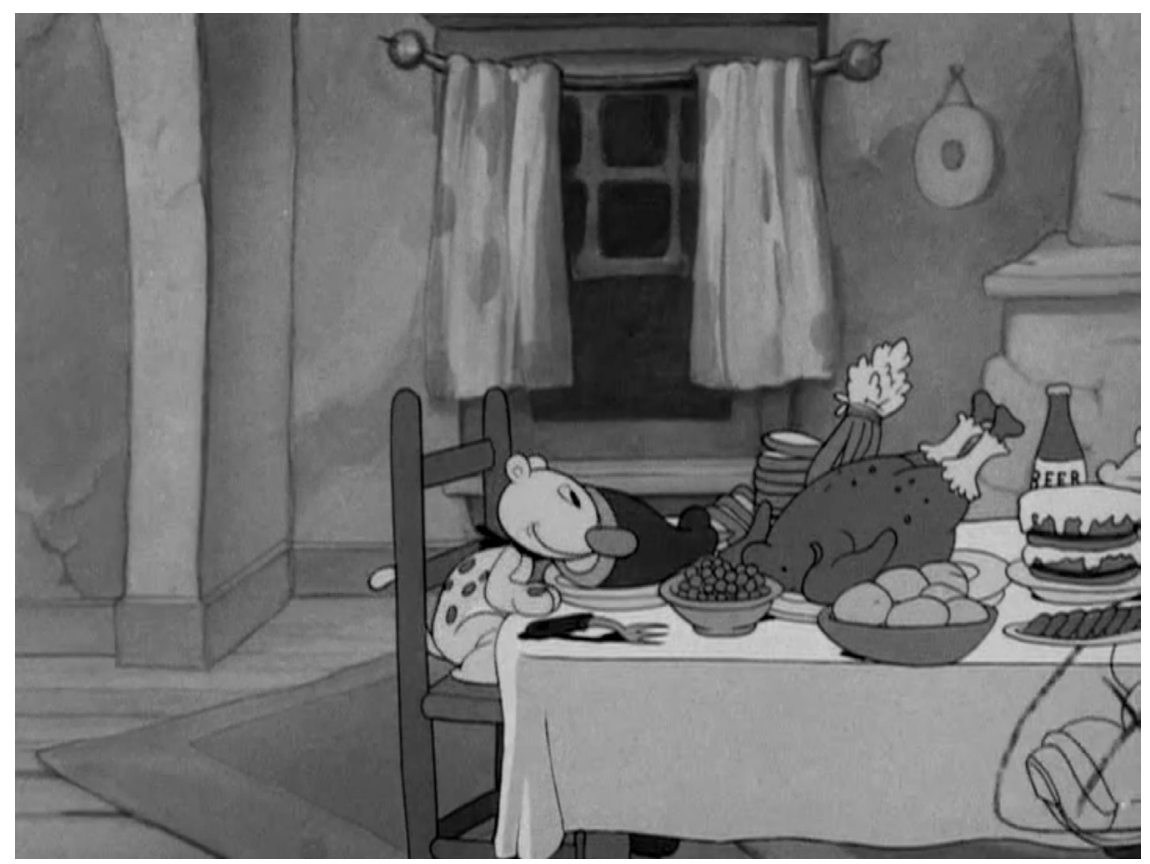

FIGURE 2.5. Popeye's leg crossed out in a frame from Popeye Presents Eugene the Jeep (Paramount, 1940).

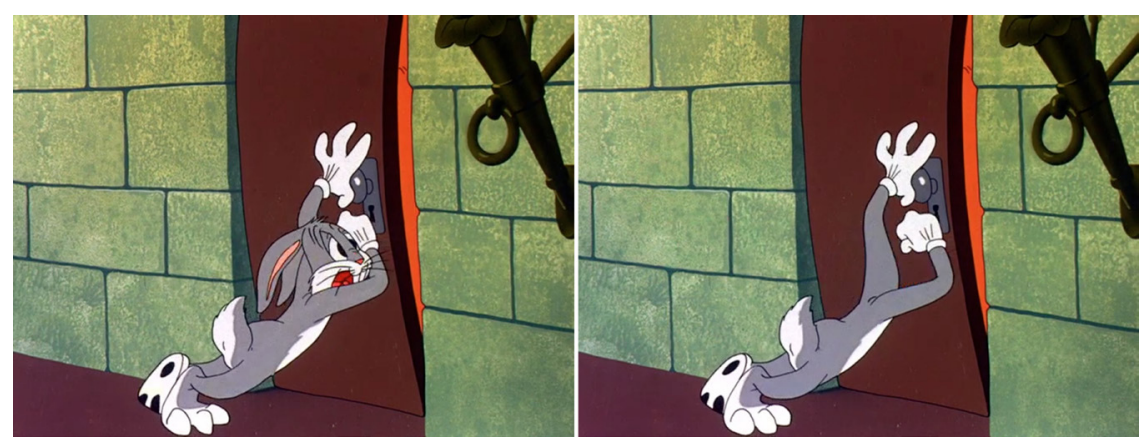

FIGURE 2.6. Bugs Bunny loses his head in Hair-Raising Hare (Warner Bros., 1946).

the inker's borders. In Freleng's Hare Do (Warner Bros., 1949), the verso side is deliberately photographed (fig. 2.7). A mass of anonymous characters repeatedly rushes in and out of a theater; the same set of cels is reused in each instance, but is flipped whenever the crowd moves left to right. Given the number of characters in the scene and the relative brevity of their appearance on-screen, the choice to save time on the inking and painting end made sense. But in Frank Tashlin's Porky 
Pig's Feat (Warner Bros., 1943), for example, we are not meant to see Daffy Duck's gloppy underside, in which his bill lacks details like lips and nostrils and his hands distinct fingers. Porky Pig, standing at the left of the frame, is painted on a separate cel, the correct side of which has been photographed: his face has carefully delineated cheeks, eyebrows, and wrinkles. By the next frame, the camera operator has righted Daffy's cel, but Porky, meanwhile, remains exactly as he was in the previous cel setup, slightly aghast at his friend's grandstanding (fig. 2.8). For an all-toobrief moment, though, we have been made privy to just what was in front of us all along, if hidden from view.

These examples, culled primarily from Warner Bros. shorts but typical of all animated cartoons of the period, do by accident what animation historian Michael Frierson would claim the films of United Productions of America, a studio that formed in the wake of the 1941 animators' strike at Disney, did on purpose: "lay bare the cel process." Frierson was describing one of the signature visual tropes of UPA cartoons like Robert Cannon's Gerald McBoing-Boing (1950) and Madeline (1952), namely, shot transitions in which the cel setup remains static as the background changes. These transitions, he writes, "are a visible reference to their mode of production, a pointed demystification of the cel process, revealing the foreground overlay and thereby detaching the character from the diegesis." Yet Frierson's argument hinges on the declaration that "cartoons are creations of the graphic arts as much as they are creations of the motion picture arts." ${ }^{66}$ One could therefore say that mispainted or misplaced cels speak not to animation's photographic nature but rather to the form's rootedness in the graphic, or what Bazin calls simply "the image." 47 But these micromovements only become visible after one admits that the animated cartoon could have a place in a photographic theory of cinema. That is, in recognizing that cel animation was never camera-less, even if it (arguably) aspired to be so, one begins to see how its individual frames offer us a unique view of physical reality.

Furthermore, many of the typical mistakes were themselves invisible to the naked eye. One would have to hold each cel up to a light to see that the paint had been inconsistently applied. The taking of the photograph is a moment of exposure, of illumination. The stack of cels before the camera is a palimpsest of opacity and transparency. Light is diffused, reflected, absorbed..$^{8}$ According to Donald Crafton, there could be up to a " 25 percent difference in illumination between the top and bottom cels in a four-layer stack." 49 The difference between layers of nitrate cels, which were used for the early black-and-white shorts, was even starker. In Hugh Harman's Ride Him, Bosko! (Warner Bros., 1932), for instance, the figures have all been painted in black and white but those on lower cels appear on-screen in shades of gray. Even if this difference in illumination was taken into account, the cels might still betray their material properties before the camera. And so, too, might even the camera, as evidenced in several Warner Bros. cartoons of the 1930 . The reflection of the camera lens hovers over the bodies of elephants in both I Love 

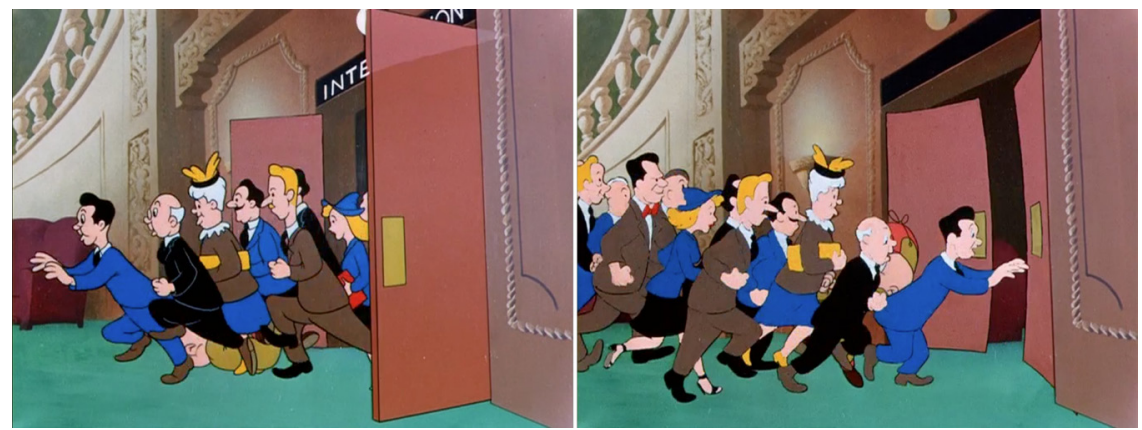

FIGURE 2.7. A cel's recto and verso sides in Hare Do (Warner Bros., 1949).
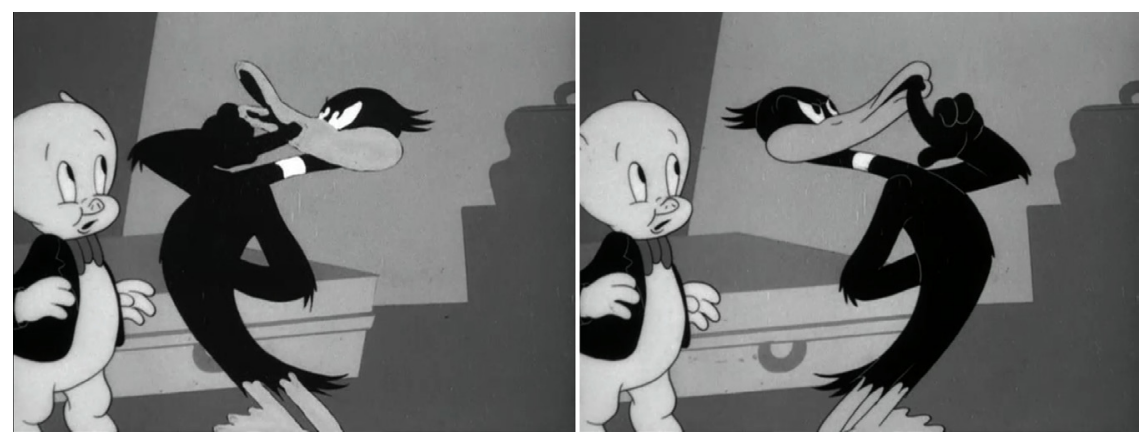

FIGURE 2.8. Successive frames from Porky Pig's Feat (Warner Bros., 1943).

a Parade (Rudolf Ising, 1932) and Buddy's Circus (Jack King, 1934) and, according to Crafton, in the panning shots of Little Beau Porky (Frank Tashlin, 1936).50

It is the photographic apparatus that not only records and reveals many of these particular mistakes but also, in fact, creates them. Before taking the photograph, the camera operator would secure the background and cels under the glass platen. If too little pressure was applied to the platen, however, the opaque, painted areas of a cel might cast a sliver of a shadow against the background, creating what Earl Hurd called in one of the first cel animation patents a "poster effect." ${ }_{51}$ Too much pressure, on the other hand, could result in a series of concentric bands called Newton's rings, an optical interference pattern that also appears on the surfaces of oil slicks and soap bubbles. But here animation's status as photography reactivates that fundamental epistemological problem, one that dovetails with aesthetic inquiry: What are we seeing? The material properties of the photographed and the material properties of the photograph cannot always be disentangled. For instance, it is often impossible to tell whether the Newton's rings were produced in front of the camera, by pressure from the platen, or still later in the production process, by a contact printer..$^{52}$ In other words, imperfections like Newton's 
rings signify another sort of close contact-the intimate connection between, or even collapsing together of, the filmed and the film. Where does one begin and the other end? Was that celluloid fiber wriggling at the side of the frame stuck in the gate of the camera in the animation studio or in the gate of the projector used for optical printing? (In Tex Avery's Magical Maestro [MGM, 1952], much to the audience's surprise, a character "plucks" just such a hair from the bottom of the screen-a graphic image can look an awful lot like a photographic one.)

Or consider, once more, the reflections from the overhead camera lights that frequently lick at the edges of the frame. These are especially prevalent in those cartoons that use nitrate instead of acetate cels. On occasion, the reflections look like (or are even indistinguishable from) the warping and bubbling of nitrate film stock, serving as a reminder that the photographed object and the film itself are, at base, one and the same: celluloid and celluloid. Like the film stock, the nitrate cels were highly combustible, and inkers and painters had to make sure the cels they were working on did not catch fire from their desk lamps. After nitrate cels had been photographed, almost all were then incinerated to clear up storage space-just as many silent films were. Cels (no matter what fantastic image they might display) were always subject to the physical and chemical laws of our world and affirm animation's double role as the photographic record of ephemeral documents - a record that is all too ephemeral in its own right, as the devastating storage vault fires at Fox in 1937 and MGM in 1967 demonstrated.

Dust specks, too, confound our ability to tell the photographed and the photograph apart. Well aware that what might go overlooked in production would be magnified thousands of times in the projected film, studios took multiple measures to keep dust and dirt from making their way into the final image. These precautions, however, were never quite enough. Barbara Baldwin, who worked as an airbrusher at Disney, recalled in a 1995 oral history that she and the other women once bought the few male employees in the Ink and Paint Departments hairnets to prevent dandruff from getting on the cels. ${ }^{53}$ This may have been a practical joke intended to further emasculate men performing what was already considered women's work, but it also reflected a real anxiety about the many ways in which a cel might be sullied. According to a 1947 article in American Cinematographer, the Camera Department at Disney's studio at Burbank housed a special cel-cleaning room, where cels were treated to discharge static electricity. ${ }^{54}$ Most camera operators were also responsible for cleaning the glass platen with an air hose between each shot. In an episode of the Woody Woodpecker Show from the 1950s, Walter Lantz offers a behind-the-scenes look at this part of the process. "If he didn't do this, every speck of dust would show up on the screen," Lantz narrates. A dust- and hair-covered image is shown. "We call it a snowstorm, and we certainly don't want this on our films." 55 The term "snowstorm" recalls the "rain effect" described by Yuri Tsivian in his work on the reception of early film in Russia. He quotes a 1916 technical manual on the effect: 
Since ... a scratch mark in the corner of the picture is rapidly followed by one in the middle or at the top, it looks as though they are dancing all over the place, sometimes in dense clusters, sometimes scattered all around the image. If there are a lot of these defects the screen will appear to be covered with a fine veil of flickering white specks, or a shower of "rain."

What distinguishes "snow" from "rain" is that the former has an existence before the camera lens, while the latter is a mark on the body of the film itself. ${ }^{57}$ One is embedded in the surface of the image, the other is on its surface. Yet they have attributes in common: in their dispersal across the screen, in their flickering dance, in their veiling of the screen. For example, in an early scene in Bill Roberts's Brave Little Tailor (Disney, 1938), Mickey Mouse fends off a swarm of cartoon flies while all around him also flit what are obviously specks of dust-he may be oblivious to them, but we are not (fig. 2.9).

Dust, in all the epistemological and ontological instability it presents (and represents), is thus an especially redolent detail. It evokes Theodor Adorno's characterization of the method guiding Walter Benjamin's Arcades Project as a "technique of enlargement," in which "small or shabby objects like dust and plush" are set into motion; plush, Benjamin writes, is "the material in which traces are left especially easily." ${ }^{58}$ Dust returns us to Dai Vaughan's observation that early film audiences were most impressed with "what would now be considered the incidentals of scenes: smokes from a forge, steam from a locomotive, brick dust from a demolished wall." ${ }_{59}$ It conjures up the physical object that animation photographically reproduces, and reminds us of what is lost in photographic reproduction. What could that dust tell us if we could see it, touch it, even inhale it? ${ }^{60}$ If "the étuis, dust covers, sheaths with which the bourgeois household of the preceding century encased its utensils were so many measures taken to capture and preserve traces," as Benjamin writes, then nitrate and acetate celluloid sheets are the plush of animated cartoons, capturing the traces of what touches them. ${ }^{61}$

Indeed, acetate is commonly used to "lift" fingerprints from crime scenes. "It is astonishing that we have so much oil in the skin of our fingers," Culhane remarks, "but even more astonishing is the ease with which it is transferred to cels." ${ }^{2}$ Like dust, fingerprints become visible only when the cel is photographed, when the light hits it in just the right way. One marks the beginning of Bob Clampett's Goofy Groceries (Warner Bros., 1941), and two oily smears drift over the Salvador Dalí-inspired world of Freleng's Dough for the Do-Do (Warner Bros., 1949). These indexical traces slipped through despite the many precautions taken by inkers and painters to avoid touching the cels with their hands, such as wearing white cotton gloves. Auril Thompson, a former painter at several studios, describes in a telling anecdote the lengths to which she went to shield her handiwork from the very hands that had worked it. A cutaway diagram of a Lockheed plane had been xerographically fixed to a four-foot-long cel, and it was her task to fill in the entire plane-the wings, the wheels, the ailerons, the cockpit, "even the little pieces of 


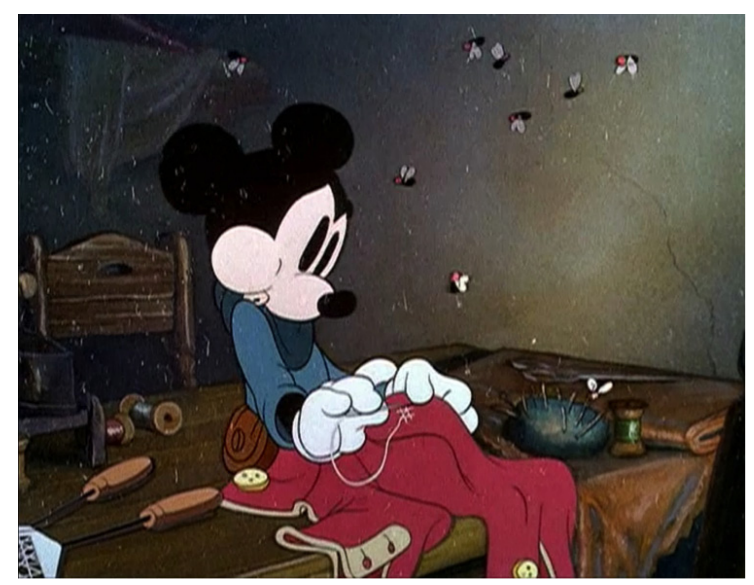

FIGURE 2.9. Dust and flies swarm around Mickey Mouse in Brave Little Tailor (Disney, 1938).

cloth that went over the seats," each with its own color. The paints she had at her disposal did not properly adhere to the cel, so she had to dilute each of the fifty different colors with soap. The one cel took her a week to finish, at which point she tried to show it to the other women in her studio. She held it up, she remembers, balancing it between her palms, so as "not to get fingerprints in it." So heavy was the cel from the paint, however, that it slipped out of her hands and, upon landing on the floor, cracked in half. ${ }^{63}$

It takes human errors such as these for animation's mechanical nature to be remembered. Each and every frame then seems haunted, not by the ethereal but by the corporeal. At any point, we sense, the world will intrude and, in the words of Siegfried Kracauer, take its "revenge upon those who dare to desert it." ${ }_{4}$

\section{“WE'RE ALL A PART OF IT"}

To locate the world in the animated cartoon is to identify the convergence of two distinct theories of cinema. The first of these is Bazinian. The second, meanwhile, positions itself as directly opposed to Bazin's putative realism. The experimental filmmaker Peter Tscherkassky offers a passionate summary of this second strand:

The iconoclasm of the avant-garde does not direct itself towards the image as such, but rather against the notion of cinematographic image being a representation of reality. The axiom of the "film as a window to the world," as it was formulated by André Bazin, defines a position opposite to that of the avant-garde. The transparent window divests the image of its essence, and it is precisely this essence which is addressed by the avant-garde: upon closer inspection, the apparent iconoclasm is 
therefore revealed as a paradoxical turning towards the image itself, whose own intrinsic reality is to be maintained. What is stressed is the character of the created object, of the produced in contrast to the apparent simplicity in the relationship between the reproduction and the reproduced. ${ }^{65}$

But the epistemological questions raised by animation - its status as both graphic and photographic, producing a world and reproducing the world-trouble the hard boundaries Tscherkassky erects between avant-garde aesthetics and realism. To better understand how these two seemingly opposed theories of cinema might ever come together, I turn now to the work of the contemporary artist Andrew Norman Wilson, whose photographic series ScanOps (2012) consists of inkjet prints of pages from books digitized by Google subcontractors. The pages selected by Wilson are all marked by what he calls "anomalies," such as text warped by software glitches, illustrations rendered as black blobs by high-contrast scans, or the hands of workers subcontracted by Google-images evocative of the examples I have culled from animated cartoons.

Wilson's Workers Leaving the Googleplex (2011), a video he covertly shot while himself a Google employee, expands the frame to include the whole of which these hands are part: the men and women, predominantly of color, who spend their days scanning page after page in a building adjacent to the storied Google "campus" in Mountain View, California. They are not, however, granted access to Google's onsite swimming pools, massage parlors, and medical care. They and their work are meant to be invisible, but Wilson's photographs disclose "the disturbances in what is supposed to be a seamless interface." ${ }^{66}$ Although their fingers are often gloved so as not to leave any telltale prints on the book they're propping open, they nonetheless make an impression of a different kind. "Simon Newcomb-49," a photograph in the ScanOps series, looks at first to be a monochromatic print, a rectangle of dark red. But in the lower left there appears a small pink ovoid spot-the tip of a finger, its loose latex covering ever so slightly wrinkled. Wilson's photograph is at once abstract, a play of color, shape, and scale, and mimetic, insofar as it is a physical reproduction of the forty-ninth page of Google's downloadable PDF of the December 4, 1909, proceedings of the Philosophical Society of Washington. Originally published as a slim volume bound in a lightweight auburn jacket, the proceedings were digitized on March 9, 2009. ${ }^{67}$ The resolution of the PDF is detailed enough to reveal the matte texture of the paper and even a faint "Harvard University Library" stamped in relief on the cover's recto side, or the sixth page of the PDF (it is also legible as a backward embossment on its verso, the seventh page of the PDF). Markings in pencil are distinguishable from those committed in ink, and no one would take the "Digitized by Google" watermark in the lower-right corner to be part of the source document. Another page from the PDF is included in the ScanOps series, but Wilson frames the two separately. Stripped of context, they become Surrealist found objects, which Wilson then recontextualizes as 
"part of the photographic apparatus, which in a broad sense includes not only the machinery but the social systems in which photography operates"-a system that comprises, as Wilson enumerates, "the anonymous workers, Google founders Sergey Brin and Larry Page, the pink 'finger condoms', infrared cameras, the auto-correction software, the capital required to fund the project, the ink on my rag-paper prints, me-we're all part of it." ${ }^{36}$

The unprecedented scope of the Google Books project makes such anomalies or disturbances inevitable. Wilson is not the only artist whose work draws attention to mistakes that punctuate this vast digital archive. For instance, Benjamin Shaykin's Google Hands (2009) is a 140-page "collection of problem pages found in Google Books," and, since 2011, Krissy Wilson has maintained a blog called The Art of Google Books, which showcases the library stamps, bookplates, inscriptions, circulation slips, and marginalia (as well as the hands) accidentally preserved in the online database. ${ }^{69}$ What sets ScanOps apart, however, is Wilson's insistence on calling what he does photography:

I'm more interested in printing the images than posting my finds online. I prefer to call what I'm collecting photographs as opposed to scans. Mass market books can be sliced open and fed into scanners, but the books I'm looking at come from library collections and need to be photographed from above... They're both indexical and medium-specific. Their processes, digital manipulations, and material supports are folded within them. ${ }^{70}$

In calling them indexical, he means to stress how they are the effect of a specific physical cause. Some of his examples also bear an iconic resemblance to their external referent (that is, we can recognize a finger propping open a page as a finger propping open a page), but others, such as the whirlpools of text that result from a glitch in the scanning software, look as much like their source as feces does a hunted fox or a column of mercury does a fever. In either case, however, the photographs qua photography testify to the existence of the world outside them. Wilson's understanding of photography is informed by the strains of art and film criticism that speak in the same breath of Bazin's "Ontology of the Photographic Image" and Roland Barthes's Camera Lucida (1980). One example is Rosalind Krauss's 1977 "Notes on the Index," a two-part essay on photography and abstract art, which declares, "It is the order of the natural world that imprints itself on the photographic emulsion and subsequently on the photographic print. This quality of transfer or trace gives to the photograph its documentary status, its undeniable veracity."11 Understood as photographs, then, the pages of Google Books function as documents of the labor and technology that made them-these processes are their salient that has been.

By "medium-specific," meanwhile, Wilson wishes to draw attention not to what the photograph represents but rather to what the photograph is made of-its material specificity. For a digital photograph, this is its ones and zeros, its vectors or rasters. The physical reality to which the photograph thereby bears witness is 
itself: it says, $I$ am here. Thus an out-of-focus or pixelated photograph has not failed to show us what we want to see but, in fact, tells us about the very stuff of the photographic apparatus, from the camera lens to the editing software. In this respect, Wilson aligns his project with the sort of modernist conception of photography articulated by Tscherkassky and other structural and experimental filmmakers, such as Peter Gidal, or Annette Michelson in her critiques of Bazin's film theory. ${ }^{72}$ As Daniel Morgan has observed, "Where Bazin and others focused on the content of the medium, on what the film showed-often phrased in terms of 'reality' or 'world' - by [the 1970s] the debate had shifted to concerns over the matter of the medium, namely the physical fact of the celluloid itself." 73 Ultimately, the two sides of the debate-Bazin's and Barthes's realism(s) on the one hand, Michelson's modernism on the other-intersect in Wilson's work. What matters to him is the photograph's status as evidence. The photograph is a fragment of the world. ${ }^{74}$

\section{TRACING TRACES}

Wilson's project helps clarify what is at stake in seeking out mistakes in animated cartoons. To see animation as photography is, as I have argued, to see the labor that went into the film's making. Each and every animated cartoon is a photographic archive, and each and every one of its constitutive frames doubles as a visual catalogue of imperfections, anomalies, and disturbances, all of which conform to Marx's "knife that fails to cut" and the "piece of thread which keeps on snapping." These mistakes "forcibly [remind] us of Mr. A, the cutler, or Mr. B, the spinner," and thereby "bring to our attention their character of being the products of past labor." 75 In the cases of both animated cartoons and Google Books, that past labor includes the labor of photography. And to see the labor of photography is to puncture the phantasmagoric spell of animated cartoons.

Of course, many animated cartoons seemed already to gesture to the world that made them. Animation has long been regarded as uniquely self-reflexive. For instance, Lev Manovich has cast "animation" against "cinema” as follows:

Animation foregrounds its artificial character, openly admitting that its images are mere representations. . . . In contrast, cinema works hard to erase any traces of its own production process, including any indication that the images which we see could have been constructed rather than recorded. ${ }^{76}$

Decades before Barry Spinello's Soundtrack (1969) attempted to let the viewer "literally see what he hears," the optical soundtrack was making cameo appearances in Fantasia (Disney, 1940), Three Caballeros (Disney, 1944), and Dun Roman's The Herring Murder Mystery (Columbia, 1943). ${ }^{77}$ Dave Fleischer's Goonland (Paramount, 1938) and Chuck Jones's My Favorite Duck (Warner Bros., 1942) showed us the filmstrip's hitherto repressed sprocket holes, just as George Landow's Film in Which There Appear Edge Lettering, Sprocket Holes, Dirt Particles, Etc. (1965) would a generation later. Or consider Chuck Jones's Duck Amuck 
(Warner Bros., 1953), a cartoon lauded for its skewering of cinematic conventions. Throughout the film, Daffy Duck is tormented by the pencil and paintbrush of an animator who, at the film's conclusion, is revealed to be none other than Bugs Bunny. ("Ain't I a stinker?" he gloats to the audience, his right hand still clasping the pencil.) Robert Stam, for one, has claimed that Duck Amuck "anticipates Persona [1966, dir. Ingmar Bergman] by incorporating projection mishaps into the film itself." 78

But, as Dana Polan has argued, Duck Amuck in fact amounts to a closed loop, a self-generated phantasmagoria in which cartoon characters create themselves. The world of Duck Amuck makes no allowances for our world. Its narrative elides the actual human labor that went into its making. By foregrounding its artifice, the cartoon paradoxically "erases any traces of its own production process." 79 The obvious artifice may be what frees it to make a joke out of "the awkward material contingency of film," but the success of such a joke depends on the film not bursting into flames. ${ }^{80}$ As the structural filmmaker Peter Gidal insists, "Optical effects are photographic inscriptions." Thus a shadow, a sprocket hole, or a splice mark "is an image, a reproduction, a photographic image, as is every cinematic device given through projection of film through a projector. This is not an ontological inference but rather a description, an effect, a determinate effect of a photochemical process." ${ }^{11}$ An animator's hands can only intervene in Goonland to piece the broken film back together if the actual film has not, in fact, broken. (And, tellingly, we can see reflections of his hands in the cels on which the images of the broken filmstrip have been painted.)

To open the loop, to restore these traces, one must watch the cartoon in the way Wilson studies Google Books-not for its putative content but for its form, the photographic medium. If understood in this way, one can learn to recognize the constructed-ness of Duck Amuck and other films in which scenes and characters appear to be painted before our eyes, such as Jones's Rabbit Rampage (Warner Bros., 1955) and Disney's Aquarela do Brasil (1942) and All the Cats Join In (1946). These films deploy what is called a "wipe-off" technique: the sequence is shot in reverse as the completed image is progressively wiped away, exposure by exposure. What this means is that we are witnessing not the painting process, as in Henri Clouzot's The Mystery of Picasso (1956), but rather the erasing process. In many instances the paint is not fully wiped off, and leaves a slight, ghostly impression on the cel. A frame from Duck Amuck is thus like a photograph of Robert Rauschenberg's Erased De Kooning Drawing (1953). A white picket fence is there but not there, the faintest of smudges. More noticeable is the difference between the cel painting that is still wet, to make the wipe-off procedure cleaner, and the cel painting that is dried. When the putative film frame collapses on Daffy's head, Bugs helpfully paints him a stick to help prop it back up. As it is being painted (or, rather, erased), the stick is yellowish brown, closer to tan. Once it has been fully painted, it takes on a hue closer to raw umber (fig. 2.10). 


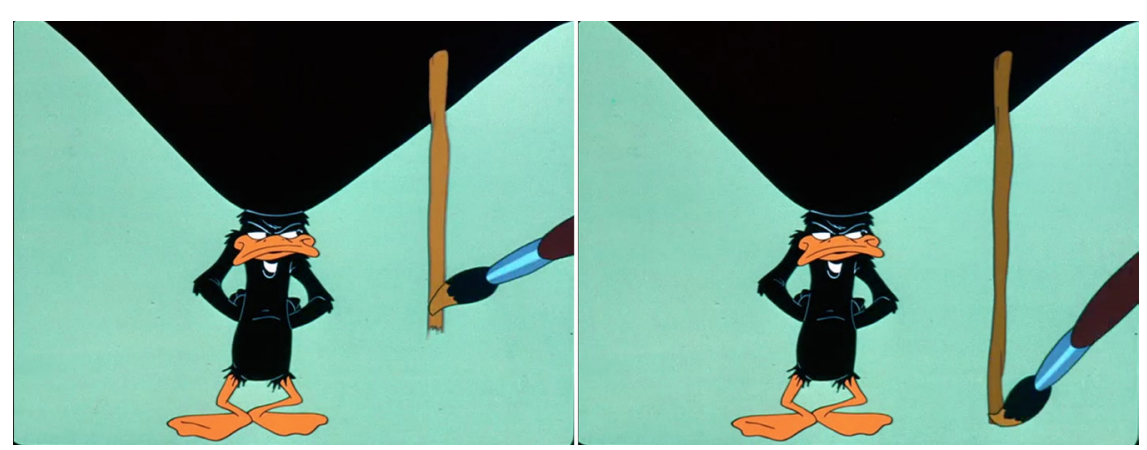

FIGURE 2.10. Successive frames in Duck Amuck (Warner Bros., 1953).

In Rabbit Rampage, it is Bugs Bunny who is tormented and Elmer Fudd who is doing the tormenting. Fudd paints hat after hat after hat on Bugs's head, each one more elaborate than the last. Because both the ink and the paint had to be wiped off, they were applied to the same side of the cel. As a result, the paint sometimes covers the inked outlines and detailing. In one frame, the paint on Bugs's hat is still wet, and its ribbons, flowers, and other embellishments lack clear, strong outlines. In the next frame, the cel has been inked and painted in the usual fashion, and the colors are darker and their boundaries more decisively delineated. Rabbit Rampage showcases many of the other mistakes endemic to the cel animation technique: when Fudd paints Bugs in triplicate, each copy is on a separate cel layer and, as a consequence, is of a slightly different shade of white and gray; the yellow tail Fudd gives Bugs is accidentally painted its usual gray for two frames; for a tenth of a second Bugs loses and then regains an arm.

I am here tracing traces-traces that intersect, overlap, disappear. They do not, however, loop back on themselves. The trail we follow leads not to a singular artist, to Bugs Bunny or to Chuck Jones, but to the whole system of markings, of tracesfingerprints pointing every which way. One is reminded of Benjamin's account of "the world" offered to children by the illustrations on their books: "The objects do not come to meet the picturing child from the pages of the book; instead, the gazing child enters into those pages, becomes suffused, like a cloud, with the riotous colors of the world of pictures." ${ }_{22}$ These cartoons-their brushstrokes, their inked lines, their erasure marks, their transparencies, their opacities-are not closed compositions. They show and they hide. They are difficult, demanding, and dense-centrifugal and centripetal.

\section{ENTERING THE PHOTOGRAPH}

In What Cinema Is! (2005), a wistful monograph on the current state of cinematographic realism, Dudley Andrew describes an encounter with the ghost of Bazin. 
The ghost takes the shape of markings in Bazin's personal copy of Jean-Paul Sartre's LImaginaire (1940). "Examining it page by page (except for those pages-very important - that he did not read: I know because they are uncut)," Andrew writes, "I found his penciled underlinings, and some marginalia." ${ }^{3}$ Andrew observes that Bazin bracketed an entire passage that he would soon repurpose for "Ontology of the Photographic Image." Then, in a description that alludes to the opening of that very essay, Andrew writes of discovering a "mummy" nestled between the pages: snatched from the flow of time, stowed away neatly at page 38 , is a sheet of notes on which Bazin had typed a list of terms from Sartre's work. ${ }^{84}$

Would this encounter have seemed as haunted if Andrew had been examining the book page by page on microfilm? That he is handling a physical object-touching what Bazin has touched, retracing the lines traced by Bazin's pencil-seems especially poignant, linked as it is to the "psychology of relics and souvenirs" that owe their power to the "transference of reality." ${ }^{5}$ Moreover, marginalia has the loose, uninhibited quality of an artist's sketch, which Christian Keathley in turn likens to the immediate power of the photograph. The sketch, Keathley claims, "gives the impression that it has been composed automatically, instantaneously, out of a desire to register the image as near as possible to the moment of its existence." This is in contrast to classical painting, which conceals its own making. Keathley then compares two works by Leonardo da Vinci in order to articulate their distinct powers: "Upon seeing the Mona Lisa, one may appreciate the extraordinarily composed image, but upon seeing Leonardo's sketchbooks in a museum case, one cannot help but also marvel, "He touched this!"'86 But if the sketch has the power of a photograph, what about a photograph of a sketch? Could a photographic reproduction of Bazin's personal copy of L'Imaginaire ever possibly give way to something akin to the awe felt by Roland Barthes upon looking at a photograph of Jérôme Bonaparte from 1852: "I realized then, with an amazement I have not been able to lessen since: 'I am looking at eyes that looked at the Emperor"'? ${ }^{87}$ Could a photograph of L'Imaginaire ever move Andrew to say, "I am looking at pages that were looked at by Bazin"?

Perhaps, however, a photographic reproduction would have led Andrew to think that Bazin's jottings were in pen and ink, not pencil, or caused him to worry that he could not distinguish between a line in the margins and a hair in the gate of the contact printer. In "tracing Bazin's traces," Andrew undoubtedly experiences the aura of this particular copy of L'Imaginaire, at least as Walter Benjamin defines the term in "On Some Motifs in Baudelaire" (1939). He invests the inanimate object "with the ability to look back" at him, to examine him just as he examines it. ${ }^{88}$ For Benjamin, as for anyone who seeks but cannot find in a photographic image the fullness of a returned gaze, the technological reproduction seems impoverished. It may compel us to look, to stare, to search, but even that which is magnified or slowed by photography remains forever at an unattainable remove. 
Adorno, upon reading a draft of Benjamin's essay on Baudelaire, sent his friend a letter inquiring about the phenomenon of the aura. "Is this concept not an indication of that moment upon which I grounded the construction of phantasmagoria in my Wagner study, namely, the moment of human labor?" he asked. "Is not the aura invariably a trace of a forgotten human moment in the thing, and is it not directly connected, precisely by virtue of this forgetting, with what you call experience?" ${ }^{89}$ Benjamin disagreed. The aura can arise even from organic objects untouched by human hands. Yet Adorno's question remains vital. Certainly the reemergence of a forgotten human moment is what pricks us in Andrew Norman Wilson's photographs. Likewise, it is what reminds us that the animated cartoon offers not a reality sui generis but in fact a view of our own world.

The photograph itself is an object with an aura. Whether projected on a screen, displayed on a computer monitor, reproduced as a halftone print, or glued to the pages of a scrapbook, a given photograph is as material as what it represents. One might, therefore, expect of a photograph the same response one would expect from a man or woman-or, as Benjamin argues, any object, organic or inorganicnamely, that it will return one's gaze. It is this materiality on which Wilson's ScanOps series is predicated. The hundreds of thousands of scanned images that comprise Google Books cannot be treated as pure text, as pure information. In printing and framing selected scans, Wilson foregrounds the material procedures and networks that constitute photography. This is not simply a matter of representing the human labor of the photograph's iconic resemblance to the world. The photographs need not be "legible" to seize us-indeed, they are often fuzzy, distorted, discolored, their putative content obscured by a software glitch or a Newton's ring. These obstructions are part of them. In fact, such interferences make us sensitive to the medium of photography itself: we only remember we are wearing glasses when they are smudged.

One thinks of Virginia Woolf's response to a screening of Robert Wiene's Cabinet of Dr. Caligari (1920). For Bazin, this was exactly the kind of film that put its "faith in the image" instead of in reality. What Woolf sees, however, is something overwhelmingly, frighteningly real:

At a performance of Dr. Caligari the other day, a shadow shaped like a tadpole suddenly appeared at one corner of the screen. It swelled to an immense size, quivered, bulged, and sank back again into nonentity. For a moment it seemed to embody some monstrous, diseased imagination of the lunatic's brain. For a moment it seemed as if thought could be conveyed by shape more effectively than by words. The monstrous, quivering tadpole seemed to be fear itself, and not the statement, "I am afraid." In fact, the shadow was accidental, and the effect unintentional. ${ }^{90}$

Woolf is (most likely) describing an obstruction in the projector's beam, an obstruction that was particular to the "performance" of The Cabinet of Dr. Caligari she happened to attend. The accident she describes is not a marginal 
detail captured by the camera. But her attention to this kind of disturbance reflects her sensitivity to the medium of cinema. ${ }^{91}$ One could imagine her being just as taken with the slight shiver in the branches that frame the face of the film's narrator in the opening scene, or with a downpour of scratches on the film print. Ultimately, in the final projected image, the difference between what is photographed and the cinematic apparatus collapses. Watching Walt Disney's All Wet (1927) on DVD has a similar effect (fig. 2.11). While Oswald the Lucky Rabbit whispers in the ear of a canine lifeguard, a jagged, black form, larger than one of Oswald's hands, appears in the corner of the screen, where it rises, falls, and then retreats. How and when did this form make its way into (or onto) the film? Its power derives from its movement, which gives it life, a life that threatens to grab Oswald and his companion.

Andrew's study of Bazin's marginalia and Woolf's fascination with this shadow are both concerned with what lies at the edge of things. Investing meaning in the peripheral, they are haunted by what others might think of as noise. Woolf in particular pushes "reality" to its limit, whereby its transient material literally overshadows its life. We might recast her suggestive commentary as the manifesto of a proto-structural filmmaker. According to Juan Suárez, structural film "acted as an un-indexing medium. It questioned and interrupted the transparency of photographic representation at every turn or, differently put, it showed that the photographic image was full of noise." The textures of certain structural films, for instance, "drew attention to the effect of time exposures and film stocks while simultaneously suggesting that photographic representation is, after all, a matter of dots dancing on an empty field." ${ }^{22}$ Woolf's monstrous, quivering tadpole presages those dancing dots. This is the stuff of cinema, its true "material density and multiplicity." ${ }^{93}$

Cinema is by its very nature an expanding universe, whether of grain or of pixels. Even the cosmos of an animated cartoon, seemingly so ordered, so controlled, so finite, is abuzz.

In animated cartoons, silver halide particles twirl in tandem with all sorts of other visual noise, from paint splatters to dirt smudges to greasy fingerprints. And dance they do, for no two film frames are alike: "The grain is different in each picture-even if it shows the same object, it is not the same picture," Werner Nekes has argued. "This becomes obvious if you just take a tiny corner of a frame and blow it up to huge proportions, you'll see the movement of the grain, which is the carrier, the material the information is transported on." ${ }^{94}$ Digital "restorations" both enable one to see more of the image and yet deepen the sense that the closer one peers, the harder it is to discern just what separates the photographic from the graphic: Is that a rippling pond, or the warping of a film print, or the swim of pixels?

To look at animation as photography is to find the world that has been cropped out of the frame. This is the Bazinian axiom of the "film as a window to the world." 95 But it is also to find the world within the image, to study the windowpane as well 


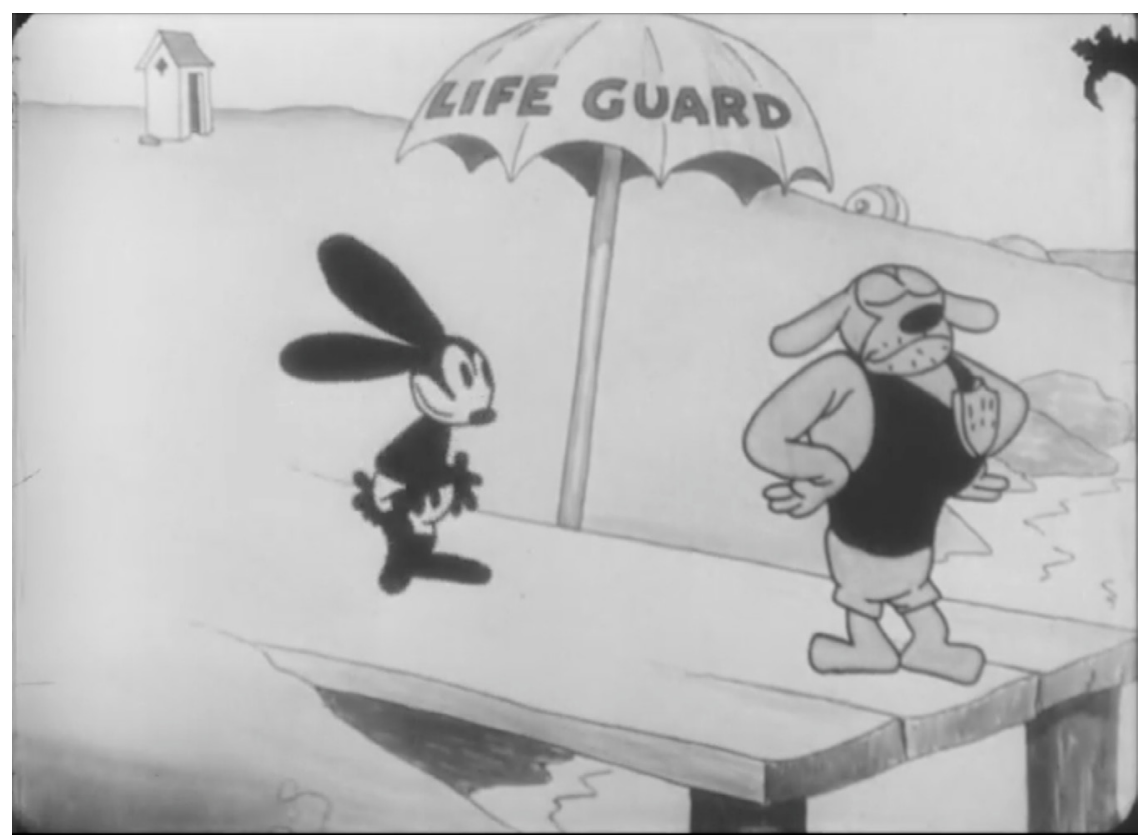

FIGURE 2.11. An obstruction in the film gate looms in the periphery of All Wet (Disney, 1927).

as the view beyond it. A cartoon documents and dramatizes India ink, watercolor paints, paper, glass, and stacks of transparent cellulose nitrate or acetate sheets; particles of dust traverse half the screen and fleeting, spectral reflections are cast by the animation stand's overhead lights; Newton's rings knit together. And yet animation betrays the graphic of the photographic. A line might be a gesture of ink, a particle of dust on the cel, a hair in the gate of the camera or the contact printer or the projector; the camera lens becomes an element to be photographed, inseparable from the other transparent plates and sheets before it; the image assimilates the various physical and chemical agents that can affect a filmstrip. The disturbing presence of scratches, stains, and grain—or are they pen strokes, paint splotches, dust specks? - do not occlude the object but instead reveal the nexus of social, technological, and economic practices that is the photographic apparatus. To penetrate the animated cartoon, one must learn to navigate the corridors of images made labyrinthine by their low resolution and to look past the dense fog of film emulsion. Through this obscurity the world comes into view. 